angina pectoris which always subsided instantaneously under amyl nitrite inhalation. But synchronously with the pain the flow also always ceased, to reappear with a fresh breast-pang two or three days later. Thus the menstrual periods became broken up and irregularly distributed throughout the month. And since they always accompanied the commencement of the flow the anginal seizures became considerably increased in number. Eventually the use of the drug was discontinued and then the menstrual process, together with the attacks of angina, slowly returned to regularity. Since then I have used amyl nitrite in the following cases of uterine hæmorrhage, and in these five cases only.

CASE 1.-A woman, aged 43 years, no family, became very anæmic and almost unable to continue her work. Inquiry elicited that for nearly a year the menstrual periods had been profuse and increasing in duration. The present period had lasted three weeks and showed no tendency to terminate. She refused examination and was consequently ordered to lie down in the afternoon and inhale three minims of amyl nitrite. The first inhalation instantaneously and completely arrested the hæmorrhage for nearly 24 hours. Bleeding then recommenced and the nitrite was repeated. The same result followed, but there was a second slight reappearance 24 hours later and she was again treated. She thus had three inhalations at intervals of about 24 hours. After this there was no further hæmorrhage for five weeks, when I lost sight of her. She had improved greatly in colour.

CASE 2.-A woman, aged 38 years, had undergone a series of operations, vaginal and abdominal, for prolapse and flexion of the uterus. As one result she became addicted to the use of morphia hypodermically. Whenever the amount injected in the day rose above two grains menstruation always ceased; she had gone 12 months without a period. In the course of reduction the flow would reappear at about the same stage-namely, two grains per diem. When eventually the drug was cut off altogether, she became regular, but the re-established periods steadily became more profuse and prolonged. Her last period had endured-for 17 days, and she was commencing to show signs of anæmia. One three-minim inhalation was then given at bed-time. This completely terminated the period.

CASE 3.-A woman, aged 28 years, had undergone the operation of removal of the vermiform appendix. One ovary and tube being found diseased were also removed. I saw her a year subsequently. She then had a considerable ventral hernia. She was also troubled with menorrhagia, associated with ovarian and sacral pain sufficient to incapacitate her for the time being. She was directed to allow each period to last three days and then terminate it by inhaling three minims of amyl nitrite at bedtime. This she found no difficulty in effecting. The ovarian and sacral pain always ceased synchrononsly with the flushing of the face and the cessation of the flow.

CASE 4.-An unmarried woman, aged 37 years, suffering from intramural fibroid. The uterus measured by the sound about five inches but there were no pressure symptoms. The menorrhagia being severe, she was obliged to pass about ten days of each month confined to her bed. She had undergone a long course of treatment by bromide of potassium, ergot, and ergotin hypodermically without apparent benefit, but she had refused to submit to any radical operation. It was found in her case that the bleeding could be completely controlled by amyl nitrite. A single inhalation could always be counted on to check hæmorrhage for at least 24 hours, provided she remained in bed or on the couch, and an average of three was sufficient to tide her over each period. Further, she was able to be up and about except for some three days each month. Some six months later $I$ was informed that the size of the uterus was materially less.

CASE 5.-An unmarried woman, aged 49 years, suffering from inoperable carcinoma of the cervix and vagina. She had had several scraping operations performed, which, however, failed to check the hæmorrhage except for quite short periods. Plugging had been resorted to on one or two occasions. Amyl nitrite in doses of from 3 to 5 minims was given by inhalation on five or six occasions. It never failed to effect an almost complete hæmostasis, lasting for from one to three days.

The rationale of the action of ampl nitrite in arresting hæmorrhage from the uterus seems simple. By dilating the arterioles generally it diminishes the peripheral resistance, Thus, it reduces the general blood pressure and thereby the vascular distension of the uterine mucosa. In this way it strikes out or modifies one of the essential factors in all uterine hæmorrhage, whether this be physiological or pathological in kind. Consequently the nature of the morbid condition primarily responsible for pathological hæmorrhage has no special bearing on the utility of the drug. Other things being equal, this should be as great in malignant disease as in mere subinvolution or the simpler forms of endometritis. Although there was no instance of failure yet the number of cases reported are inadequate to settle definitely the permanent place to be accorded to amyl nitrite in uterine hæmorrhage. But I am in hopes that some of those who have greater opportunities will take up the matter and test it systematically. It seems not unlikely that some cases of fibroid disease in which hæmorrhage is the sole dangerous symptom may be by means of amyl nitrite tided over until the menopause without the necessity for any major operation. And there are always some patients who refuse to submit to surgical treatment.

Meantime a few obvious dangers may be mentioned. The very facility with which uterine hæmorrhage, normal or abnormal, is checked may become indirectly a source of danger. The sudden arrest of the normal menstrual flow may be fraught with serious sequelæ. The use of the drug by the patient herself may lead to the deferment of a highly necessary examination in cases of carcinoma. I have in one case seen this tendency exhibited already. Finally, in cases of advanced malignant disease there is often already present a very low blood-pressure, and it may be that the further sudden reduction consequent on inhalation of the nitrite would actually endanger life. This point has been referred to by Leonard Williams in commenting on the routine treatment of phthisical hæmoptysis by amyl nitrite. Yet, so far as I know, no disaster has yet been recorded which could clearly be ascribed to the drug.

July 28th, 1908.

I am, Sir, yours faithfully,

\section{A QUESTION OF COMPENSATION.}

\author{
Io the Editor of THE LANCET.
}

SIR,-I think you will agree with me that the facts of the following case are so important to governors of hospitals, trustees of nursing institutes, and others who have insured their employees under the Employers' Liability Act that they ought to be generally known. One of the nurses connected with the Beccles Nursing Institute had the misfortune to infect her eje while attending a case of purulent ophthalmia in an infant. Purulent ophthalmia was in consequence set up in the nurse's eye. This was followed by panophthalmitis and it was necessary to remove the right eye in order to save the sight in the remaining organ. This nurse was insured under the Employers' Liability Act and the premium paid was $7 s$. 6d. per cent. on her wages per annum. On applying to the insurance office for compensation the trustees of the Nursing Institute were informed that under the Act there is no compensation for pain and suffering, disfigurement, or anything of the kind, but that she was simply entitled to half the loss of earnings; that the directors of the office considered that the nurse would be as well able to earn her living as a nurse with one eye as with two; that they did not consider themselves bound to make any payment to her, but as a matter of charity they offered her 20 guineas and this they subsequently increased to 30 guineas. The nurse had claimed $£ 50$. This offer of the directors was by their advice submitted by the trustees to a solicitor and his opinion was that it should be accepted, as although he thought that the view taken by the directors might not be correct, yet he was very doubtful whether the nurse would succeed in any action for damages. The trustees therefore accepted the offer made.

If this interpretation of the law be correct it would seem that the accidents to which nurses are especially liable, such as that which occurred in this case, pyæmia, \&c., are not provided for, and it would seem desirable either that a test case should be tried to determine the meaning of the Act, or that those having to insure nurses should find some sort 
of policy which would cover these risks. Possibly there may be some association with which $I$ am unacquainted which watches over the interests of nurses and which provides for these contingencies.

I am, Sir, vours faithfully,

W. M. Crowfoot, M.A., F.R.C.S. Eng.

Beceles, Augugt 3rd, 1908.

\section{STUDY OF TROPICAL MEDICINE IN LIVERPOOL. \\ To the Editor of THE LANCET.}

SrR, - I beg to call your attention to the new course of instruction which will be given to the students of the Liverpool School of Tropical Medicine at the University of Liverpool after the beginning of next year. For a considerable period the teachers of the school have reported to the committee of the school that the time allotted for the course of instruction-namely, the academical term, or about ten weeks-was insufficient to give a complete curriculum on the subject, especially as, owing to the recent numerous great advances in our knowledge of tropical medicine, the subject had been very much enlarged of late. The school therefore has determined to add three weeks to the ten weeks' period of study, and the University has decided to give its Diploma in Tropical Medicine only to students who had undergone this course of 13 weeks. It is hoped that this change will result in still more complete instruction and a still more valuable diploma.

Owing, however, to the lengthened term it will not be possible to give more than two such courses every year, and the courses have therefore been fixed to begin on Jan. 6th and Sept. 15th every year, the corresponding examinations for the diploma being held 13 weeks later - that is to say, about April 5th and Dec. 13th respectively. In addition, however, to these two full courses the school has arranged to introduce an innovation in the form of a short course lasting only one month for practical instruction in tropical pathology and medical entomology, to be given from June 1st to 29th every year. It is hoped that this will be of the greatest utility to medical men returning on short leave to England, as it will enable them to acquire the practical technique of microscopic and similar work which has been much desired by many of them. After the four weeks' short course a class examination will be held and a certificate will excuse for the first four weeks of the full Lent and autumn courses.

The University and the school desire to have this information regarding the changes referred to spread as widely as possible for the use of medical men in the tropics, and I am therefore to request you, Sir, to be kind enough to give some notice of it in your valuable periodical.

I am, Sir, yours taithfully,

Liverpool. ALFRED L. JoNES, Chairman.

\section{EVIDENCE OF HOUSE PHYSICIANS AND HOUSE SURGEONS IN CASES OF ATTEMPTED SUICIDE, ETC.}

\section{To the Eaditor of THE LANCET.}

SIR,-My attention has recently been again attracted to the inconvenience at hospitals resulting from the necessary (or unnecessary) attendance of members of the resident stafl at law courts to give evidence in cases of attempted suicide, \&c. The following is an instance which has just occurred at the hospital to which I am attached. Twice recently a young woman has been brought to the hospital after attempting suicide by swallowing a little carbolic acid or Iysol, and on each occasion she had to be admitted for a day or two. On both occasions also the house physician was afterwards obliged to give up his work at the hospital owing to a "subpcria" to attend at the law court. Yesterday he had to be away from 9.30 A.M. to 5.30 P.M., and as the case did not come off he had to leave the hospital again this morning. at 9.30 A.M. The inconvenience caused to the working of one of the smaller hospitals by this kind of thing is obviously very great. In regard to the case of an insane woman who unsuccessfully attempted to murder her children and commit suicide one of the house surgeons had to attend at the Central Criminal Court on four days from about 10 A.M. to
4 or 5 P.M. before the case was heard. When at last this case came on it was finished in a. few minutes without the house surgeon's spoken evidence being taken. Cannot anything be done to minimise the difficulties arising at small hospitals in this way?

I am, Sir, yours faithfully,

F. PARKes Weber, M.D. Cantab.

Harley-street, W., July 30th, 1908.

\section{THE DAIRIES SUPERVISION ACT IN NEW SOUTH. WALES. \\ To the Editor of $\mathrm{THE}$ 工 ANCET.}

SIR,--As a veterinary surgeon and an officer of the Board of Health I cannot but note with satisfaction the increased attention which appears to be arising in England on the subject of dirty and tuberculous milk and I have thought that a short account of what is done in N'ew South Wales to insure purity of milk-supply might be of interest.

In 1901 an Act entitled the Dairies Supervision Act was passed to consolidate various enactments regulating the production, manufacture, and distribution of milk and its products. The administration of the Act was charged to the local authorities-in towns the municipal councils thereof and in districts beyond those boundaries the senior police officer of the district-and their principal duties are laid down as being the keeping of a register of all persons engaged in the production of milk or cream or in the manufacture of butter or cheese for sale or supply for profit and conducting quarterly inspections of the premises, appliances, and cattle of all such persons. To the local authorities are granted powers of entry and of taking samples of milk and its products or of water from any water-supply used on the premises; to enforce cleanliness and good sanitary conditions on any premises; to close any polluted source of water-supply; and to refuse or to cancel the registration of anyone whose premises are insanitary or who refuses to carry out any order for the improvement of these conditions. Any dairyman, \&c., trading without being registered is liable to a penalty not exceeding £20. Regulations have been issued under the Act defining the necessary conditions to be observed in building cowsheds, milk-rooms, \&c. ; for maintaining them in a sanitary condition; for the keeping of pigs; to prevent the use of milk from diseased animals and forbidding the employment of any person suffering from any infectious disease. In addition to the supervision of the local authority the Board of Health by means of a staff of veterinary and dairy inspectors maintain a direct control over both the registered premises and the manner in which the local authorities carry out their duties.

The improvement brought about by this Act in the whole of the great dairying industry and the milk traffic of the State has been very great within the last few years, and tuberculous cattle amongst dairy herds are becoming greatly lessened in numbers as more and more are slaughtered every year under the supervision of the veterinary inspectors. As a result of the demonstration given by those officers dairymen are beginning to grasp the fact that it is essentially the best policy for themselves to keep their herds free from this disease apart from any question of public health. Fines for any breach of the regulations can be inflicted not exceeding £20. Lacking though it is in many essentials, the Act has the great merit of being compulsory, and the adoption of its provisions is not left to the discretion of any body of self-inflated aldermen as is too often the case with measures of public health.

I am, Sir, yours faithfully,

MAX HENRY, M. R. C. . S

Veterinary Inspector New South Wales Board of Health. Candelo, New South Wales, June 13th, 1908.

\section{THE TREATMENT OF MALIGNANT PUSTULE ("GRANO MALO").}

\section{To the Editor of THE LANCET.}

SIR,-Bearing on an article that appeared in THE LANCET of Feb. 29th by Dr. J. S. Clarke and a note by Dr. John Cropper in THe LANCET of April 4th, the following data from the province of Buenos Aires may be interesting 